\title{
Maternal control and self-control in the 3-year-old child
}

\author{
RUBY A. PEELE \\ University of North Carolina, Chapel Hill, North Carolina 27514 \\ and \\ DONALD K. ROUTH \\ University of Iowa, Iowa City, Iowa 52242
}

\begin{abstract}
A situation was observed in which mothers were asked to control their preschool children's behavior. In a playroom divided into four parts by tape on the floor, each quadrant contained a table and chair, with toys on either three or all four of the tables. The mother was asked to attempt to keep her 3-year-old child from crossing the dividing lines and playing with toys in the three quadrants designated off limits. Although the availability of nonforbidden toys had only a marginal effect, the mothers were significantly able to decrease their children's activity. Mothers whose children entered off-limits areas of the room most often spent the most time issuing instructions and commands to the child. Children who spent the most time vocalizing seemed to have the best self-control, that is, spent the least time playing with forbidden toys. The measures of child noncompliant behaviors were significantly correlated with each other. Other techniques used by mothers included distraction, retrieval and holding, reasoning, and bargaining.
\end{abstract}

This study focused on the interaction of mothers and children in a standard playroom situation. Its purpose was to examine the methods used by mothers in keeping 3-year-old children within a restricted area of the room, in situations where toys were or were not available to the child. In a review by Lytton (1971) of observational studies of parent-child interaction, it was remarked that such structured situations had not been used "in the study of such behavior socialization by parents as reaction to misdemeanor" (p. 664). The present study, by setting up parental demands which the child was likely to violate, permitted the observation of the way both the mother and the child dealt with the situation.

An initial study by Routh, Schroeder, and O'Tuama (1974) using this playroom situation found that instructions given to a child by the experimenter to remain within one section of the room produced a decrease in the number of lines on the floor crossed within a 15-min period, compared to the child's behavior under free-play instructions. Barkley and Routh (1974) found that modeling and the promise of contingent reward were also effective in reducing the locomotor activity of shildren in such a situation. However, Stolz (1967), in a survey of parents' perceptions of their child-rearing practices, found that the parents saw little connection between punishment, reward, and learning in relation to teaching their children new tasks. Thus, besides finding sut what procedures used by experimenters influence shildren's behavior in this situation, we need to study he strategies used by parents, and the reactions of the shildren to parental attempts to control their behavior.

Appreciation is expressed to Barclay Martin, Gary Mesibov, nd Harriet Rheingold for their comments and to Doris Kistler, low ard Peele, and Sally Peele for help in carrying out the study. 'he research was supported by USPHS Maternal and Child lealth Project 916 and by Grants HD-03110 and ES-01104 from IIH. Request reprints from Donald K. Routh.
Our interest in this type of study came partly from a concern with the clinical problem of hyperactivity, its relation to normal child development, and the practical problems faced by the parents of a hyperactive child. The Routh et al. (1974) study supported a developmental view of hyperactivity by showing that, in this standard playroom, normal children showed a steady decrease in locomotor activity with increasing age. The playroom-observational procedure has also been validated as a measure of hyperactivity (Routh \& Schroeder, 1976). Observations such as those in the present study are also of interest in relation to the everyday problems of parents of young children. Situations occur daily in which parents cannot allow their children to be as physically active as they may desire.

Our own first studies were concerned with the behavior of the child alone in the playroom, rather than the mother-child dyad. It was soon discovered, however, that 3-year-olds and younger children often become distressed when left alone in the room, and thus we became involved in studying the mother and child together. Belkin and Routh (1975), in a study of the effects of the presence of the mother on the behavior of 3-year-old children, noted that even though the mothers were instructed to minimize their interaction with their children, they found this difficult to do. Instead, they watched, smiled, and replied to the child's communications. Thus, in the present study, we were careful to include measures of the mother's behavior as well as that of the child.

In the experimental part of the present study, it was hypothesized that children would be more active (make more quadrant changes) in the no-toys-present condition than in the toys-present condition. It was expected that the mothers would find it necessary to spend more time engaging the children in appropriate 
activity and in talking to keep the children from making quadrant entries when no toys were present in the part of the room to which they were restricted.

\section{METHOD}

\section{Subjects}

Twenty-four 3-year-old children and their mothers from the Chapel Hill, North Carolina area served as subjects. The parents of the children were contacted by phone and given a brief but straightforward description of the procedures involved. There were 13 boys and 11 girls, whose mean age was 43.6 months, with a range from 36 to 47 months. No child had any outstanding behavioral problems (defined as a history of referral for professional help) or any gross sensory or motor deficiency or known neurological abnormality. The families were all intact, with both parents residing together at the time the study was conducted. The median occupation of the fathers was professional or managerial, and the median educational level for fathers was a graduate or professional degree. The mothers' modal occupation was housewife, and the mothers' median education was a college degree.

\section{Apparatus}

The apparatus was basically the same as that of the Routh et al. (1974) study. The playroom was divided into four parts by strips of tape on the floor, with a table and chair in each quadrant. The usual toys were laid out in sequence on the tables in the three quadrants of the room far from the door. In the quadrant next to the door, there were two chairs (for the child and the mother), a magazine, and, for the toys-present condition, the same toys as in the other quadrants. In the no-toys condition, the set-up was identical except that there were no toys available in the quadrant next to the door.

\section{Procedure}

Before the subjects' arrival, a random assignment was made as to the sequence of experimental conditions (toys present, no toys present; or no toys present, toys present) for a particular mother-child dyad. Then the mother and child were seen in an office before the playroom sessions and given an explanation of what was to take place, and what the mother was to try to do. A copy of the following instructions was given to the mother and discussed with her: "We are interested in assessing maturity levels of the average 3-year-old child. Maturity will be measured by the ability of the child to withstand the temptation to play with off-limits toys and obey the parent's wishes to remain in a given area. Children of this age were chosen specifically because of their notorious knack of getting into everything. There are times of course when it is necessary for a child to contain his exploratory drive. Many parents have experienced this when they are in the grocery store and the little one is grabbing everything from the shelves. It is of interest to us to observe and record how progressive a child this age is in dealing with the conflict of playing with the toys as he/she wishes or pleasing his/her parents by remaining in the approved area. Of course, no child this age would be able to resolve this effectively without the help of his/her mother; therefore, it is up to you as a mother to provide the necessary control your child relies on. When you go into the room, you will notice that it is divided into four sections. Within each quadrant is a table with various toys arranged on top. You are to communicate to your child that he/she is not to cross the dividing lines for any reason (this includes to play with any of the toys). Whatever method you use to communicate this instruction and further control your child is up to you. We encourage you, however, to be natural and spontaneous, behaving as you would under normal circumstances when faced with this problem. Remember that the child is free to do anything he/she likes as long as he/she remains within his/her quadrant. Are there any questions?"
After it was clear that the instructions were understood, the mother and child were taken to the playroom and left alone. Before leaving, the experimenter said: "This is the room. You will notice four quadrants marked with black lines. May I remind you that anything you do with your child is all right as long as the two of you remain within the first section. Again, I encourage you to interact freely with your child."

At the conclusion of the first 15 -min session, one of the observers set up the room appropriately for Session 2. For this session, the mother was told, "The instructions are the same as before, only this time there (will be) (will not be) toys present." After the second session, the mother was asked to fill out a brief questionnaire, but the results of this questionnaire are not the focus of the present report, and no more will be said of it here.

\section{Observational Measures}

Three child behaviors and seven parent behaviors were continuously recorded by two observers sitting behind a one-way mirror, using a 20-pen Esterline-Angus event recorder. The definitions of the measures and their interobserver reliabilities (Pearson product-moment correlation coefficients) were:

1. Time spent by child touching any forbidden toy $(\mathrm{r}=1.00)$.

2 . Time spent by child in any type of vocalization (as defined by Belkin \& Routh, 1975) $(\mathrm{r}=.93)$. This referred mainly to talking but also included singing, whistling, and unintelligible vocal sounds.

3. Quadrant changes (as defined by Routh et al., 1974) $(\mathrm{r}=.99)$.

4. Time spent by parent in instruction and command $(r=.87)$. This category applied to behaviors ranging from the parent's informing the child of the area in which he/she was allowed to play to teaching the child how to operate a toy.

5. Time spent by parent praising child $(r=.90)$. Time rather than frequency was utilized because the content ir addition to the incidence of praise was of interest. This category was employed to indicate the amount of verbalized positive reinforcement the mothers used.

6. Time spent by parent in vocal disapproval or criticism $(r=.92)$. The amount of time a mother spent verbally repri manding or punishing her child was recorded in this category

7. Time spent by parent in other conversation $(r=.97)$

8. Time spent by parent in physical contact (contact initiatec by mother $)(r=.99)$.

9. Time spent by parent engaging child in appropriate activit! $(r=.99)$. Any effort on the mother's part to interest the chili in any activity that did not involve crossing lines or touchin the forbidden todys in an attempt to distract him/her fron forbidden activities was recorded in this category.

10. Time spent by parent reading magazine $(r=.99)$.

It was often necessary to code an activity of the parent it more than one category. For example, if a mother sang, witl accompanying gestures, the song, "This is the way we wash ou clothes...," this was recorded both as "other conversation' and "engaging child in appropriate activity." After each session a written account of the interaction between mother and chilc was entered into a journal to provide supplemental information

\section{RESULTS}

The first analysis concerned the effects of sex o child, experimental condition (toys present vs. no toy present), and sequence of experimental conditions of th 10 behaviors coded. The time measures were, in effec proportions of the $15-\mathrm{min}$ session, and such proportior are, in principle, not normally distributed. In this mult variate analysis, therefore, an arc-sine transformatio was applied to all nine time measures (but not, c course, to the quadrant change measure). The multivar 
ate effects of sex of child, experimental condition, and sequence of experimental condition were nonsignificant, as were the interactions of these variables.

Ideally, the study should have included a third experimental condition in which the mother was not instructed to control her child's behavior. Although such a condition was not part of the present study, the Belkin and Routh (1975) study did include a condition of exactly this kind, in the same experimental setting. The use of comparison data from that study enables one to assess, at least crudely, the effectiveness of these mothers in restricting their children's activity. As shown in Figure 1, when mothers were left with their children and instructed to interact as little as possible, the children had a mean number of quadrant changes of 17.21 , significantly more than the mean of 4.15 quadrant changes for the combined experimental conditions in the present study, in which the mothers were asked to restrict their children's activity $[\mathrm{t}(41)=2.86, \mathrm{p}<.01]$.

A correlational analysis was also performed. Table 1 shows the intercorrelations among the 10 child and parent measures obtained. In examining Table 1, we might initially consider the intercorrelations among child behaviors. The two measures of noncompliant behavior, quadrant changes and time spent touching forbidden toys, were positively related to each other. In addition, there was a negative correlation between vocalizations by the child and quadrant changes (i.e., children who vocalized a lot tended to cross fewer quadrant lines).

Next, consider the relationship between child and parent variables in Table 1 . Only one parent measure (time spent in instruction and command) related to the child's behavior. Mothers whose children spent more time touching forbidden toys tended to spend more time instructing and commanding their child. Mothers whose children crossed more quadrant lines also spent more time in instruction and command of the child.

Last, looking at the intercorrelations of parent variables, it is seen that these were relatively independent of each other. The only significant correlation was the positive relationship between other conversation and time spent engaging the child in appropriate activity.

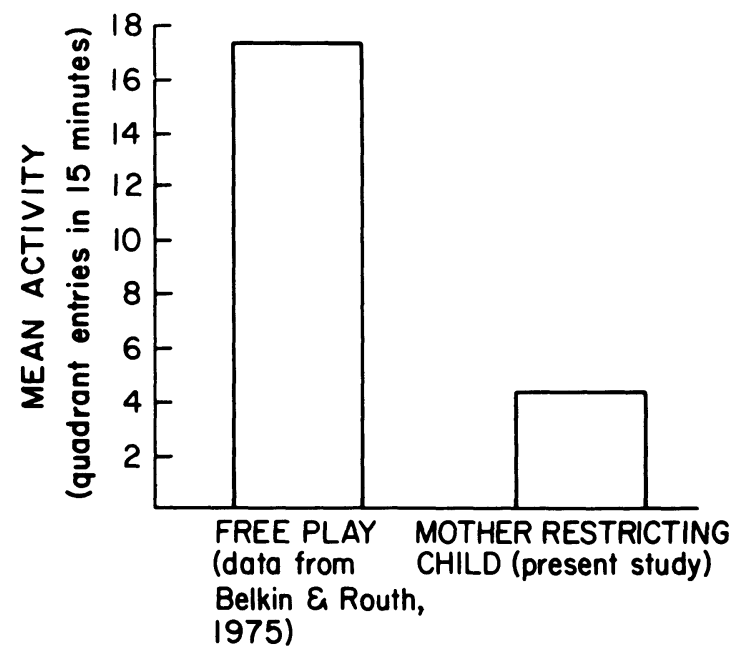

Figure 1. Number of quadrant changes by the child in a 15-min session as a function of instructions given to the mother.

\section{DISCUSSION}

In the present study, mothers were effective in minimizing the number of quadrant changes made by their children, at least in comparison to control data from another study (Belkin \& Routh, 1975). However, the experimental manipulation (toys available vs. no toys available in the quadrant where the child was supposed to stay) did not have a significant effect. Neither the sex of the child nor the sequence of experimental conditions was an important factor in the results.

Of course, the study was not done just to show that mothers can control their own children, but to determine how they do so. In examining the strategies used by these mothers, our attention is drawn mainly to the correlational analysis, supplemented by the descriptive journal.

The only maternal behavior which was correlated with child behaviors was time spent in instruction and command. One possible interpretation emphasizes the child as a cause of the mother's behavior, along the lines of Bell's (1968) well-known "reinterpretation of the direction of effects in studies of socialization." Thus, one might say that whenever the child stepped into an off-limits area or played with a forbidden toy, the mother responded by telling him or her to "stop that" and return to the approved quadrant. After all, Routh et al. (1974) did find that instructions were an effective way to reduce quadrant changing behavior in children over a wide age range. Alternatively, one might say that certain mothers often attempt control by the use of instructions and commands, or verbal

Table 1

Correlations Among the Measures

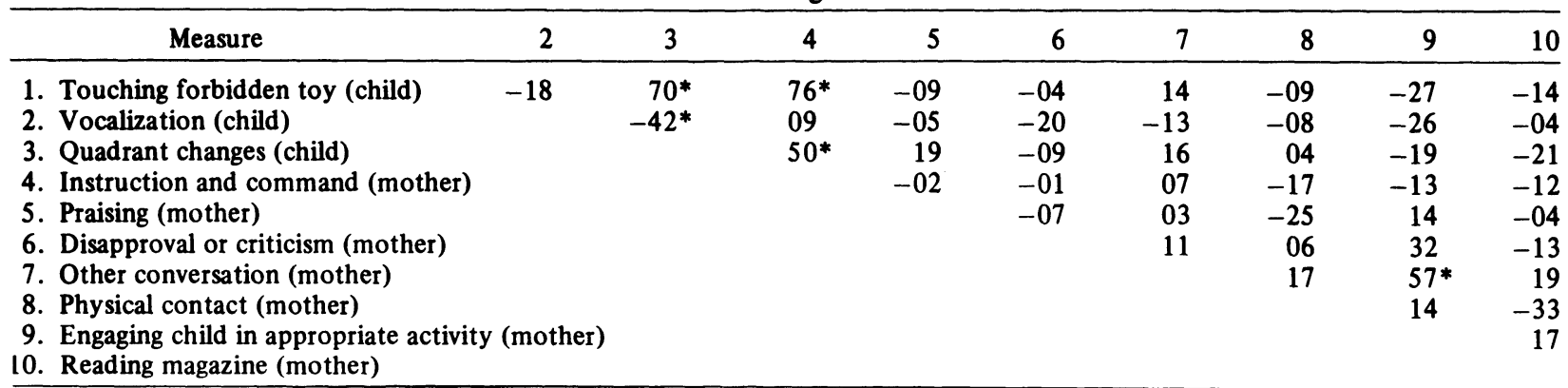


power assertion, and that this style of socialization ultimately results in a child who misbehaves more than other children. Some recent research seems to be in line with this style-ofsocialization interpretation. Forehand, King, Peed, and Yoder (1975), for example, found that mothers who brought their children to a psychology clinic with the primary complaint of noncompliance to parental commands showed a higher rate of commands in a playroom observation session than did nonclinic control mothers. Similarly, Lytton and Zwirner (1975) found that in home observations, children were most likely to comply after parental suggestions and less likely to comply after parental commands. Of course, the child-as-cause and style-of-socialization interpretations are not mutually exclusive, and both may in fact be correct.

The finding that children who made more quadrant changes also tended to spend more time playing with forbidden toys is an almost inevitable result of the way these two variables were defined (i.e., the child had to cross at least one line to get to any forbidden toy). Thus, at most, this correlation provides reassurance about the reliability of the behavioral coding system used.

The inverse relationship of child vocalization and time spent playing with forbidden toys is intriguing. Apparently, the child's vocalization may be viewed as being related to the degree of self-control of which the child is capable. Since the child's vocalization did not relate to any maternal behavior, self-control may be involved. This measure, the time spent by the child in any type of vocalization, has been used productively in other studies in our laboratory. Belkin and Routh (1975) found that 3-year-olds in a playroom with their own mother vocalized significantly more than they did when alone in the room or with a stranger, and viewed vocalization as one index of the child's attachment to the mother. In a more recent study (Routh \& Belkin, Note 1), this same vocalization measure showed a significant developmental increase over the ages 10 months to 5 years, when measured with the child and the mother in a toy-filled playroom. Thus, playroom vocalization seems to be a behavior which develops steadily during the preschool years and is related to mother-child attachment and to the child's self-control.

Some of the maternal behaviors did not seem to be correlated with the children's behaviors. In this situation, few mothers reinforced their children verbally for their appropriate behavior. Punishment in the sense of vocal disapproval or criticism was also infrequent. These observations are consistent with the finding of Stolz (1967) that parents saw little connection between reward, punishment, and their children's learning.

The particular behavior categories used in this study, however, clearly did not capture in detail the strategies used by the mothers, some of which were quite ingenious. Using descriptive journal, it is possible to give a more extended account of the strategies used. For heuristic purposes, the four basic types of strategies might be categorized as: (1) distraction, (2) retrieval and holding, (3) reasoning, and (4) bargaining.

Many mothers distracted their children from the forbidden toys by attempting to interest them in some nonforbidden activity, at times using any feature of the room to engage the child in play. One mother and her child made faces at each other in the one-way mirror. Several mothers thumbed through the magazine which was provided, pointing out animals and colors. One parent even moved the table in the approved quadrant out of the way and had her child jump from tile to tile to see how far or how high he could go. One mother-child pair engaged in singing a song about the body, touching each body part as it was referred to in the song. The story of "Little Red Riding Hood" was enacted by one mother and child. Another pair played Doctor, with the child using the magazine to fashion a "cast" for the mother's "hurt leg." These distraction tactics seemed to be effective in maintaining the child's interest sufficiently to keep him or her from making quadrant changes, at least to the naive observer. However, the behavioral code, "time spent by parent engaging child in appropriate activity" did not relate significantly to any child behavior. Perhaps the code was defined too broadly. At any rate, the children whose mothers used a distraction strategy seemed to have a happy experience in the playroom.

The second type of strategy, retrieval and holding, might be defined as any attempt by the mother to retrieve the child who had crossed a line or to physically restrain the child from crossing a line. This strategy was seldom observed. The retrieval and holding strategy seems to be a refinement of the behavior code, "time spent by parent in physical contact (contact initiated by mother)" which, it will be recalled, was unrelated to the child behaviors in the present study.

The strategy of reasoning with the child was quite popular. In this approach, the mother tried to make clear to the child why the restraint on his behavior was necessary. One mother gave this straightforward explanation to her child, "See that mirror? There are people behind it watching to see if 3-yearold children obey their mothers." Several mothers told their child that the off-limits toys were for some other child.

Bargaining strategy usually involved promising the child some reward contingent upon the child's good behavior. It is distinct from "time spent by parent praising child" in that social or other rewards are not given during the session but are promised later. This procedure (promise of contingent reward) has been shown experimentally to be effective in reducing quadrant changes in the playroom (Barkley \& Routh, 1974).

In summary, the present study found that mothers were effective in controlling their children's activity. The only maternal behavior which was correlated with child behaviors was time spent in instruction and command. Vocalization by the child was inversely related to time spent by the child playing with forbidden toys but unrelated to maternal behavior, suggesting some kind of self-control process was involved.

\section{REFERENCE NOTE}

1. Routh, D. K., \& Belkin, E. P. Development of activity, conventional play, and vocalization in infants and preschoolers. Paper presented at the meeting of the American Psychological Association, Washington, D.C., September 4, 1976.

\section{REFERENCES}

BARKLEY, R. A., \& Routh, D. K. Reduction of children's locomotor activity by modeling and the promise of contingent reward. Journal of Abnormal Child Psychology, 1974, 2, 117-131.

Belkin, E. P., \& Routh, D. K. Effects of presence of mother versus stranger on the behavior of three-year-old children in a novel situation. Developmental Psychology, 1975, 11,400 .

BELL, R. Q. A reinterpretation of the direction of effects in studies of socialization. Psychological Review, 1968, 75, 81-95.

Forehand, R., King, H. E., Peed, S., \& Yoder, P. Motherchild interactions: Comparison of a non-compliant clinic group and a non-clinic group. Behavior Research and Therapy, 1975, 13, 79-84.

LyTTON, H. Observational studies of parent-child interaction: A methodological review. Child Development, 1971, 42, 651-684.

LytTon, H., \& ZWIRNER, W. Compliance and its controlling stimuli observed in a natural setting. Developmental Psychology, 1975, 11, 769-779.

Routh, D. K., \& SChroeder, C. S. Standardized playroom measures as indices of hyperactivity. Journal of Abnormai Child Psychology, 1976, 4, 199-207.

Routh, D. K., Schroeder, C. S., \& O’Tuama, L. A. Development of activity level in children. Developmenta Psychology, 1974, 10, 163-168.

Stolz, L. M. Influences on parent behavior. Stanford California: Stanford University Press, 1967.

(Received for publication February 2, 1978.) 